\title{
Clima de escola e táticas de gestão de conflito - Estudo quantitativo com estudantes portugueses
}

\section{School Climate and Conflict Management Tactics - A Quantitative Study with Portuguese Students}

\section{Clima escolar y tácticas de gestión de conflictos - Estudio cuantitativo con estudiantes portugueses}

\author{
Pedro Cunha' ${ }^{1} \mathrm{ORCID}$ - Ana Paula Monteiro ${ }^{2} \mathrm{ORCID}$ - Abílio Afonso LourençO ${ }^{3} \mathrm{ORCID}$ \\ 'Universidade Fernando Pessoa, ${ }^{2}$ Universidade de Trás-os-Montes e Alto Douro, ${ }^{3} \mathrm{CIPE}$ - Centro de Investigação em Psicologia e Educação \\ Portugal
}

Correspondência data:

Recebido: noviembre 20 de 2015.

Aceito: julio 19 de 2016.

\section{Citação:}

Cunha, P., Monteiro A.P. , \& Lourenço, A. (2016). Clima de escola e táticas de gestão de conflito - Estudo quantitativo com estudantes portugueses. Rev. CES Psicol., 9(2), 1-11.

\section{Open access}

(c) Copyright

Creative commons

Publicações ética

Revisão por pareses

Gestión por Open Journal System

ISSN: 2011-3080

DOI: http://dx.doi.org/10.21615/ cesp.9.2.1

Sobre os autores:

1. Professor com agregação e investigador

Faculdade de Ciências Humanas e Sociais, Universidade Fernando Pessoa

Redes: Researchgate

Ação

\section{f日G.}

\section{Resumo}

0 artigo trata de uma investigação quantitativa dedicada a analisar a relação entre clima na escola e táticas de gestão de conflito. 0 estudo foi realizado com uma amostra de 348 alunos de escolas públicas de Portugal. Em contexto de sala de aula foram aplicados a CTS (Conflict Tactic Scale), - CLES (Questionário do Clima de Escola) e uma ficha de dados pessoais e escolares (para analisar as variáveis sexo, ano de escolaridade, número de reprovações e horas de estudo). Os resultados demonstram que a utilização de táticas não violentas (negociação e discussão) na gestão dos conflitos interpessoais influencia positivamente o clima de escola. Apontam ainda para relações estatisticamente significativas entre o sexo e as estratégias não violentas, entre o sexo e violência física, entre violência emocional e clima de escola e entre violência física e clima de escola. São ainda indicadas as implicações para a realidade estudada nas escolas.

Palavras-chave: Gestão de Conflito, Clima de Escola, Escola.

\section{Abstract}

This paper introduces a quantitative research addressed to analyse the relationship between school climate and conflict management strategies. The study was conducted with a sample of 348 students from public schools in Portugal. CTS (Conflict Tactic Scale), the CLES (Questionário do Clima de Escola) and a personal and academic data sheet to study variables such as gender, year of schooling, number of failures, and attendance hours. The results demonstrate that the use of nonviolent tactics (negotiation and discussion) in the interpersonal conflict management with students, impacts positively the school climate. Additionally, the results indicate the existence of statistically significant relationships between sex and nonviolent strategies, between sex and physical violence, between emotional violence and school climate $(\alpha=-11 ; p=.043)$ and between physical violence and school climate $(\alpha=-11 ; p=.035)$. The paper also indicates the implications into the school context.

Keywords: Conflict Management, School Climate, School Environment, School. 
Pág 2

\section{Professora auxiliar e investigadora \\ Escola de Ciências Humanas e Sociais- Departamento de Educação e Psicologia, Universidade de Trás-os- Montes e Alto Douro Perfil: Scholar \\ 3. Professor titular e investigador CIPE - Centro de Investigação em Psicologia e Educação Agrupamento de Escolas Alexandre Herculano Redes: Linkedin}

\section{Resumen}

El artículo presenta una investigación cuantitativa dedicada al análisis de la relación entre clima en la escuela y tácticas de gestión del conflicto. El estudio se realizó con una muestra de 348 alumnos de escuelas públicas de Portugal. En el contexto del aula de clase se aplicaron la CTS (Conflict Tactic Scale), el CLES (Questionário do Clima de Escola) y una ficha de datos personales y escolares (para analizar las variables sexo, año de escolaridad, número de reprobaciones y horas de estudio). Los resultados evidencian que la utilización de tácticas no violentas (negociación y discusión) en la gestión de los conflictos interpersonales de los alumnos influencia positivamente el clima de la escuela. También presentan relaciones estadísticamente significativas entre sexo y estrategias no violentas, entre sexo y violencia física, entre violencia emocional y clima de escuela e entre violencia física y clima de escuela. Finalmente, se indican las implicaciones para la realidad estudiada en las escuelas.

Palabras-clave: Gestión del Conflicto, Clima Escolar, Ambiente Escolar, Escuela.

\section{Introdução}

O clima de escola tem sido objecto de um grande número de pesquisas realizadas por diversos autores (Antunes, 2002; Paiva \& Lourenç0, 2011; Peterson \& Skiba, 2001; Steffgen, Recchia, \& Viechtbauer, 2013). Estudar o clima é pertinente atendendo à singularidade única de cada organização. 0 clima escolar pode ser definido como a perceção dos sujeitos acerca das relações interpessoais que estabelecem no contexto escolar e do contexto no qual essas interações ocorrem (Hoy \& Miskel, 2005). Refere-se ao sentimento que se vivencia quando se participa das atividades, das normas e crenças que operam no sistema escolar (Cornejo \& Redondo, 2001).

É, assim, o elemento distintivo das organizações e é através dele que se podem captar as expectativas (explícitas ou implícitas) dos seus atores, as normas e os valores partilhados (Barros, 2010; Blaya, 2008; Hoy \& Miskel, 2005; Revez, 2004).

Entende-se o clima de escola como fruto da individualidade pessoal, das interacções no sistema psicossocial (no quadro das suas atividades formais e informais), dos processos de influência, convicções, expectativas e valores. As representações do clima de escola têm como resultado as reações afetivas e os comportamentos e atitudes dos seus membros. 0 clima constitui um elo entre a estrutura organizacional da escola, a liderança exercida e o comportamento e a atitude de todos os atores educativos.

O clima tem sido relacionado com inúmeras variáveis, nomeadamente a violência (Steffgen et al., 2013), a satisfação na escola (Zullig, Huebner, \& Patton, 2011), o (in) sucesso dos alunos, tanto no campo cognitivo como afetivo (Paiva \& Lourenço, 2010), a transição para um novo ciclo de estudos (Freiberg, 1998) e os comportamentos de risco (LaRusso \& Selman, 2011).

Segundo Brunet (1995), comportamentos, estrutura e processos influenciam as dimensões do clima escolar. Dentro dos vários processos, o nosso destaque específico vai para a gestão de conflitos, uma vez que são escassos os trabalhos que centram a sua atenção na relação entre gestão de conflitos e clima de escola (LaRusso \& Selman, 2011). 
Para gerirem os conflitos interpessoais que surgem no contexto escolar os jovens podem recorrer a diferente táticas, mais ou menos competitivas ou cooperativas.
Atualmente, o conflito é compreendido como fazendo parte da natureza organizativa da escola, assumindo-se como uma das suas dimensões mais relevantes (Torrego, 2007) e estabelecendo-se como um elemento necessário que pode atuar como força motivadora de mudança e desenvolvimento.

Assim, estão em desenvolvimento abordagens que procuram respostas e eficácia na ação construtiva na gestão dos conflitos. Trata-se de uma área em evolução no contexto educativo, dado ser um campo particularmente pertinente para as escolas devido ao papel formativo e educativo que as mesmas assumem na vida de todos os atores que nelas participam.

A teoria do conflito (e.g. Straus, Hamby, Finkelhor, Moore, \& Runyan, 1998) sustenta que este é uma parte integrante de toda a interação humana, todavia recorrer à violência como meio de lidar com o conflito já não o é. Nas escolas, os jovens envolvemse em conflitos interpessoais devido à preocupação em conseguir o que desejam para si e à diversidade de relações que têm que estabelecer no seu contacto com os outros (LaRusso \& Selman, 2011).

Para gerirem os conflitos interpessoais que surgem no contexto escolar os jovens podem recorrer a diferente táticas, mais ou menos competitivas ou cooperativas. Entre as primeiras, o uso da violência física e emocional pode ser frequente. Nas segundas, destacam-se as táticas não violentas que traduzem comportamentos de negociação e de discussão positiva sobre os assuntos em litígio.

Para Martínez Zampa (2005), a maneira de lidar com o conflito no interior da escola diverge de um ambiente para outro de acordo com o modo como este é encarado, isto é, se como instrumento de crescimento ou se entendido como um problema que deva ser abafado.

Os comportamentos de negociação e discussão permitem encontrar uma solução que beneficia os implicados, favorecendo o seu desenvolvimento pessoal e social (ou seja, a solução é justa, proporcional e equilibrada para ambas as partes) (Torrego, 2007).

Segundo Cascón (2001), quanto maior a importância atribuída aos objetivos a alcançar e à preservação da relação entre as partes, mais relevantes são as premissas da colaboração e da não-violência enquanto princípios fundamentais no mundo da educação.

Acresce que o clima da escola contemporânea é o resultado da convivência no mesmo espaço físico, de uma multiplicidade social e cultural, com interesses e desejos diferentes, ocasionando situações de discordância e conflito.

Por outro lado, o clima de escola constitui-se como um fator potenciador de comportamentos e atitudes, contribuindo para a qualidade relacional no seio organizacional, facilitando ou dificultando a integração e o bem-estar dos diferentes atores educativos (Revez, 2004).

Tendo em vista a argumentação apresentada e a necessidade de investigar sobre tais questões, este estudo tem por objetivo principal analisar a relação entre clima de escola e as táticas de gestão de conflito. É ainda objetivo deste estudo verificar o efeito de algumas variáveis pessoais e escolares (sexo, ano de escolaridade, horas de estudo e número de reprovações) nas táticas de gestão de conflito. 


\section{Método}

\section{Participantes}

Foi usada uma amostra de 348 alunos, de escolas públicas de Portugal. Relativamente à amostra, 168 (48.3\%) alunos são do sexo masculino e 180 (51.7\%) do feminino, cuja média de idades é de 17 anos ( $D P=1.256)$. Frequentam o $10^{\circ}$ ano de escolaridade $142(40.8 \%)$ alunos, o $11^{\circ}$ ano 91 (26.1\%) e o $12^{\circ}$ ano $115(33.1 \%)$ e as idades estão compreendidas entre os 15 e os 22 anos.

\section{Instrumentos}

A escala Conflit Tactit Scale - CTS (Straus, 1979; Straus et al., 1998), tem por base teórica a teoria do conflito e o seu objetivo é medir a ocorrência e a frequência de comportamentos utilizados durante um conflito interpessoal. Encontra-se traduzida e aferida para a realidade portuguesa (Martins, 2005) e a versão utilizada é constituída por apenas 12 itens distribuídos por três dimensões: Estratégias não violentas - ações desenvolvidas para resolver um conflito através da negociação e discussão; Violência Emocional - atos verbais e não-verbais que são capazes de magoar o outro; e Violência Física - atos que incluem violência física, e apresenta-se num formato Likert de 5 pontos, desde Nunca (1) até Sempre (5). Os 12 itens que constituem a escala são apresentados em ordem hierárquica de aceitabilidade social e, atendendo à especificidade do contexto escolar, são os que se adequam aos objetivos da presente investigação.

A CTS revela-se um instrumento apropriado para a avaliação de conflitos e tem sido utilizada em várias investigações, com diversas áreas de aplicação, funcionando como uma escala adequada para a obtenção de respostas seguras e céleres no que respeita ao objecto de estudo em questão (Martins, 2005; Straus et al., 1998).

O Questionário de Clima de Escola - CLES (Antunes, 2002) avalia as representações acerca do clima de escola dos alunos do 3. ${ }^{\circ}$ Ciclo de Enseñanza Básica -CEB- e Ensino Secundário, no sentido de mapear os seus pontos fortes bem como as suas fragilidades nas diferentes dimensões em avaliação: Condições gerais - analisam o ambiente escolar geral e as condições de aprendizagem que a escola proporciona; Relações interpessoais - avaliam o contributo pessoal de cada aluno para o bom ambiente de aprendizagem ou trabalho na escola, bem como a qualidade do relacionamento que se observa entre os diferentes intervenientes na comunidade escolar; Regras - referem-se à aceitação de regras na escola por parte dos alunos e ao cumprimento das mesmas; Tempo ocupado - avalia a opinião dos alunos em relação à duração dos intervalos e à carga horária semanal; e Indisciplina - faz referência à opinião dos alunos em relação à indisciplina na escola e à sua contribuição para um mau ambiente escolar. 0 questionário apresenta 22 itens distribuídos por 5 dimensões, num formato Likert de 5 pontos, desde Discordo completamente (1) até Concordo completamente (5).

Foi ainda aplicada uma Ficha de Dados Pessoais e Escolares (FDPE) para avaliar as variáveis incluídas no modelo de equações estruturais hipotetizado, nomeadamente o sexo, o ano de escolaridade, o número de reprovações e as horas de estudo.

\section{Procedimentos}

Após a obtenção da autorização para a aplicação dos questionários e de uma breve explicação aos alunos quanto aos objetivos e preenchimento dos mesmos, procedeu-se à respetiva administração. Foram os próprios inquiridos que preencheram 
os questionários, tendo sido solicitado que respondessem com o máximo de sinceridade, tentando não esquecer nenhum item. Os alunos foram bastante recetivos, tendo sido garantidos os procedimentos éticos convencionais, designadamente a confidencialidade das respostas e a voluntariedade na participação. Os instrumentos foram administrados em contexto de sala de aula e o tempo de aplicação foi de 20 a 30 minutos, tendo-se tido em atenção o nível etário dos alunos e o ano de escolaridade frequentado.

\section{Hipóteses}

Recorreu-se a um modelo de equações estruturais (Lowe, Winzar, \& Ward, 2007; Ullman \& Bentler, 2004) para averiguar as táticas adotadas pelos alunos na resolução de conflitos interpessoais que se relacionam com o clima na escola, assim como a relevância de algumas variáveis selecionadas (sexo, ano de escolaridade, número de reprovações e horas de estudo) na utilização dessas mesmas táticas (cf. Figura 1). A curiosidade científica recaiu em cruzar essas variáveis, o que traduz um tema pouco estudado e, em certa medida, original, pois as táticas definidas no modelo CTS foram, sobretudo, analisadas em contexto diferente do escolar (cf. Straus et al., 1998).

Nesta sequência foram formuladas as seguintes hipóteses de trabalho:

H1. As raparigas utilizam mais estratégias não violentas que os rapazes como táticas de resolução de conflitos.

H2. As raparigas utilizam menos a violência emocional como tática de resolução de conflitos, relativamente aos rapazes.

H3. As raparigas utilizam menos a violência física como tática de resolução de conflitos, em relação aos rapazes.

H4. Os alunos do $12 .^{\circ}$ ano utilizam mais estratégias não violentas como táticas de resolução de conflitos do que os restantes anos de escolaridade.

H5. Os alunos do $12 .^{\circ}$ ano utilizam menos a violência emocional como tática de resolução de conflitos do que os restantes anos de escolaridade.

H6. Os alunos do $12 .^{\circ}$ ano utilizam menos a violência física como tática de resolução de conflitos do que os restantes anos de escolaridade.

H7. Os alunos que mais reprovam utilizam menos estratégias não violentas na resolução de conflitos.

H8. Os alunos com mais insucesso académico utilizam mais a violência emocional como táticas de resolução de conflitos.

H9. Os alunos com maior número de reprovações utilizam mais a violência física como tática de resolução de conflitos.

H10. Os alunos que investem mais tempo no seu estudo utilizam mais estratégias não violentas como táticas de resolução de conflitos.

H11. Os alunos que investem mais tempo no seu estudo utilizam a menos violência emocional como tática de resolução de conflitos. 
H12. Os alunos que investem mais tempo no seu estudo utilizam menos a violência física como tática de resolução de conflitos.

H13. A utilização, por parte dos alunos, de estratégias não violentas, influencia positivamente o clima de escola.

H14. 0 uso, por parte dos alunos, de violência emocional, influencia negativamente o clima de escola.

H15. A utilização, por parte dos alunos, de violência física, influencia negativamente o clima de escola.

A técnica de modelação de equações estruturais possibilita avaliar as relações causais entre variáveis inferidas (não diretamente observadas) através de um conjunto de variáveis observadas que servem de marcadores de cada variável inferida ou latente. De acordo com Byrne (2001), esta técnica tem vantagens sobre outras técnicas, tais como: a) salienta que a variância não é estável ao longo do tempo; b) possibilita calcular os erros das medidas (variáveis observadas); e c) permite calcular, rapidamente, a significância estatística de cada efeito causal e o ajustamento global do modelo hipotético. Se o ajustamento global do modelo testado for apropriado, aprovam-se as relações ou efeitos apresentados pelo modelo.

\section{Resultados}

Após a recolha dos dados, fez-se a sua aplicação no modelo (cf. Figura 1), tendo como referência os construtos e as dimensões a eles associados.

Figura 1. Especificação pictórica do modelo das relações causais com os valores estandardizados

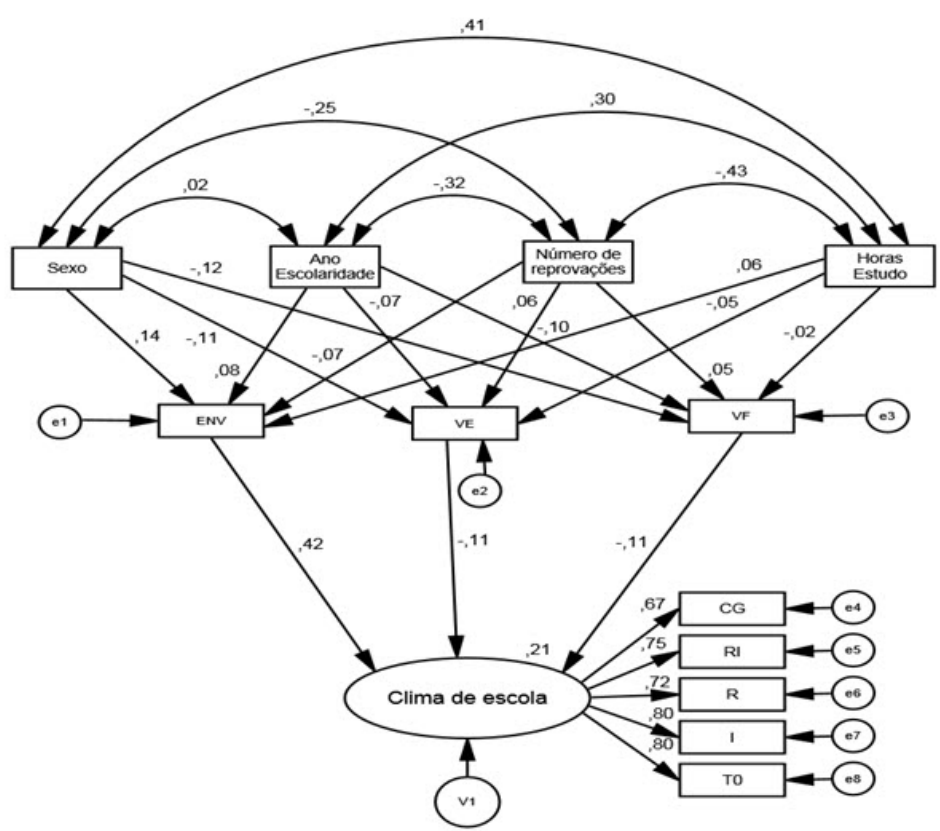

Legenda: V1=Variância residual da variável latente Clima de Escola; a letra (e) seguida de um número $(1,2, \ldots)$ diz respeito ao erro de medida da variável observável respetiva; ENV= Estratégias não violentas; VE=Violência emocional; VF= Violência Física; CG=Condições Gerais; RI=Relações Interpessoais; R=Regras; I=Indisciplina; TO=Tempo Ocupado. 
Pág 7

Na tabela 1 podem observar-se os dados descritivos (mínimos, máximos, média, desvio-padrão, assimetria e curtose) correspondentes às variáveis incluídas no modelo de equações estruturais. Tomou-se como critério o estabelecido por Curran, West e Finch (1997), que consideram que valores de assimetria maiores que 3 e de

Tabela 1. Estatística descritiva (mínimo, máximo, média, desvio-padrão, assimetria e curtose) correspondente às variáveis incluídas no modelo de equações estruturais

\begin{tabular}{lcccccc}
\hline Variável & Mínimo & Máximo & Média & DP & Assimetria & Curtose \\
\hline Número de Reprovações & 0 & 4 & .67 & .836 & 1.119 & .811 \\
Horas de Estudo & 0 & 30 & 6.44 & 7.16 & .996 & .087 \\
Condições Gerais (CG) & 9 & 45 & 25.62 & 16.13 & .149 & -1.798 \\
Relações Interpessoais (RI) & 7 & 35 & 20.65 & 12.37 & .020 & -1.806 \\
Regras (R) & 2 & 10 & 5.76 & 3.51 & .113 & -1.780 \\
Tempo Ocupado (TO) & 2 & 10 & 4.96 & 3.46 & .608 & -1.451 \\
Indisciplina (I) & 2 & 10 & 5.47 & 3.50 & .340 & -1.679 \\
Estratégias Não Violentas (ENV) & 3 & 15 & 7.16 & 5.16 & .668 & -1.379 \\
Violência Emocional (VE) & 4 & 25 & 10.78 & 7.42 & .371 & -1.776 \\
Violência Física (VF) & 5 & 25 & 12.82 & 9.33 & .477 & -1.719 \\
\hline
\end{tabular}

A avaliação dos resultados da contrastação do modelo de equações estruturais é baseada em dois critérios: nível global de ajustamento do modelo e significância dos coeficientes de regressão calculados. curtoses maiores do 10 não devem ser considerados. Na amostra, nenhuma variável revela valores próximos de tais critérios, pelo que se justifica proceder à estimação do ajuste do modelo.

A figura 1 especifica o modelo hipotetizado para os alunos da amostra. As relações causais possíveis são as constantes no modelo conforme as hipóteses delineadas no início da investigação.

A avaliação dos resultados da contrastação do modelo de equações estruturais é baseada em dois critérios: nível global de ajustamento do modelo e significância dos coeficientes de regressão calculados. Os índices de bondade de ajustamento global do modelo proposto são muito robustos ( $\chi^{2} / \mathrm{gl}=1.850 ; \mathrm{GFI}=.964 ; \mathrm{AGFI}=.930 ; \mathrm{CFI}=.967$; $\mathrm{TLI}=$ 946; RMSEA=.049), confirmando a hipótese de que o modelo proposto representa as relações entre as variáveis existentes na nossa matriz empírica.

Da análise da tabela 2 e da figura 1 pode concluir-se que as hipóteses que orientaram as especificações foram todas confirmadas, sendo estatisticamente significativas as relações entre o sexo e as $\operatorname{ENV}(\alpha=.14 ; p=.019)$, entre o sexo e VF ( $\alpha=-.12$; $\mathrm{p}=.033)$, entre VE e o clima de escola $(\alpha=-.11 ; \mathrm{p}=.043)$ e entre a VF e o clima de escola $(\alpha=-.11 ; p=.035)$. Quanto às variáveis exógenas, da análise da tabela 2, poder-se-á ainda referir que à medida que se progride na escolaridade os alunos reprovam menos ( $\alpha=-.32$ ) e dedicam mais tempo ao estudo ( $\alpha=.30)$. Constata-se, também, que os alunos que apresentam um maior número de reprovações são os que investem menos tempo no seu estudo ( $\alpha=-.43$ ). Os alunos do sexo feminino estudam mais $(\alpha=.41)$ e reprovam menos $(\alpha=-.25)$.

Relativamente às correlações múltiplas quadradas, estas indicam que a variável clima de escola é explicada em cerca de $21 \%\left(\eta^{2}=.206\right)$, diretamente pelas ENV em $5.6 \%\left(\eta^{2}=.056\right)$, pela VE em 3.9\% $\left(\eta^{2}=.039\right)$ e pela VF em $3.8 \%\left(\eta^{2}=.038\right)$. 
Pág 8

Tabela 2. Resultados da contrastação da estrutura de covariância (valor e erro estimado e nível de significância) hipotetizado para a amostra

\begin{tabular}{|c|c|c|c|c|c|}
\hline Hipóteses & & $\begin{array}{c}\text { Valores não } \\
\text { estandardizados }\end{array}$ & $\begin{array}{c}\text { Valores } \\
\text { estandardizados }\end{array}$ & $\begin{array}{l}\text { Erro de } \\
\text { estimativa }\end{array}$ & $\boldsymbol{p}$ \\
\hline $\mathrm{H} 1$ & Sexo $\rightarrow$ Estratégias não violentas & 1.398 & .14 & .597 & .019 \\
\hline $\mathrm{H} 2$ & Sexo $\rightarrow$ Violência Emocional & -1.582 & -.11 & .865 & .067 \\
\hline $\mathrm{H3}$ & Sexo $\rightarrow$ Violência Física & -2.323 & -.13 & 1.089 & .033 \\
\hline $\mathrm{H} 4$ & Ano de escolaridade $\rightarrow$ Estratégias não violentas & .497 & .08 & .341 & .145 \\
\hline H5 & Ano de escolaridade $\rightarrow$ Violência Emocional & -.627 & -.07 & .494 & .205 \\
\hline $\mathrm{H} 6$ & Ano de escolaridade $\rightarrow$ Violência Física & -1.044 & -.10 & .622 & .093 \\
\hline H7 & Número de reprovações $\rightarrow$ Estratégias não violentas & -.414 & -.07 & .369 & .262 \\
\hline H8 & Número de reprovações $\rightarrow$ Violência Emocional & .565 & .06 & .535 & .291 \\
\hline H9 & Número de reprovações $\rightarrow$ Violência Física & .598 & .05 & .674 & .375 \\
\hline $\mathrm{H} 10$ & Horas de estudo $\rightarrow$ Estratégias não violentas & .045 & .06 & .045 & .324 \\
\hline $\mathrm{H} 11$ & Horas de estudo $\rightarrow$ Violência Emocional & -.052 & -.05 & .066 & .435 \\
\hline $\mathrm{H} 12$ & Horas de estudo $\rightarrow$ Violência Física & -.021 & -.02 & .083 & .803 \\
\hline H13 & Estratégias não violentas $\rightarrow$ Clima de escola & .875 & .42 & .122 & .000 \\
\hline $\mathrm{H} 14$ & Violência emocional $\rightarrow$ Clima de escola & -.156 & -.11 & .077 & .043 \\
\hline \multirow[t]{7}{*}{ H15 } & Violência Física $\rightarrow$ Clima de escola & -.129 & -.11 & .061 & .035 \\
\hline & Sexo $\rightarrow$ Ano de Escolaridade & .009 & .02 & .023 & .711 \\
\hline & Sexo $\rightarrow$ N. ${ }^{\circ}$ de Reprovações & -.104 & -.25 & .023 & .000 \\
\hline & Sexo $\rightarrow$ Horas de Estudo & 1.449 & .41 & .207 & .000 \\
\hline & Ano de Escolaridade $\rightarrow$ N. ${ }^{\circ}$ de Reprovações & -.229 & -.32 & .040 & .000 \\
\hline & Ano de Escolaridade $\rightarrow$ Horas de Estudo & 1.816 & .30 & .343 & .000 \\
\hline & N. ${ }^{\circ}$ de Reprovações $\rightarrow$ Horas de Estudo & -2.588 & -.43 & .349 & .000 \\
\hline
\end{tabular}

\section{Discussão}

Focalizando a nossa atenção na análise do papel das táticas de gestão de conflito no clima de escola os resultados desta investigação apontam para que o emprego de estratégias não violentas, assentes na negociação, influenciam positivamente o clima de escola e o emprego de estratégias de violência (emocional e física) influenciam negativamente o clima de escola. Assim, importa realizar aqui algumas considerações referentes aos resultados encontrados. Em primeiro lugar, alunos e professores devem poder aspirar a um ambiente escolar com a necessária tranquilidade, seguro, que thes faculte uma convivência interpessoal de consideração pela dignidade humana e cidadania, expressa pela aceitação e o acolhimento das diferenças individuais, variáveis fundamentais para uma vivência construtiva do conflito e para a efetivação das atividades de ensino e de aprendizagem. Em segundo lugar, as escolas ao desenvolverem estratégias explícitas de resolução de conflitos incre- 
As escolas não são simplesmente um lugar para aquisição de conhecimentos, mas também um ambiente de aprendizagem de competências de relacionamento interpessoal. Neste contexto, os jovens desenvolvem diálogos, constituem-se em grupos, aceitam as diferenças nas motivações e comportamentos entre os indivíduos e retiram satisfação em estar e vivenciar diferentes situações com os seus pares. mentam nos jovens capacidade de resiliência, de promoção e de preservação das relações interpessoais (Costa \& Matos, 2006). Esta dinâmica constituirá um forte instrumento de proteção e prevenção de situações conflituosas no futuro, e consequentemente de construção de climas escolares positivos.

No que concerne às relações entre sexo e táticas de gestão de conflito, o presente estudo revelou que as raparigas utilizam mais estratégias não violentas e menos violência emocional e física que os rapazes como táticas de resolução de conflitos. Ayas, Deniz, Kanag e Kenç (2010) apontam neste mesmo sentido, destacando que enquanto as raparigas usam táticas de cooperação e de evitação, os rapazes recorrem a táticas mais competitivas. Tais diferenças refletem um processo de educação diferencial resultando em modos diferentes de atuar nas situações de conflito.

Quanto às relações entre ano de escolaridade, número de reprovações, horas de estudo e táticas, interessava apenas inferir uma primeira análise sobre o assunto. Os resultados indicam para que existam diferenças entre as mesmas, mas nenhuma é estatisticamente significativa na amostra selecionada.

\section{Conclusões}

As escolas não são simplesmente um lugar para aquisição de conhecimentos, mas também um ambiente de aprendizagem de competências de relacionamento interpessoal. Neste contexto, os jovens desenvolvem diálogos, constituem-se em grupos, aceitam as diferenças nas motivações e comportamentos entre os indivíduos e retiram satisfação em estar e vivenciar diferentes situações com os seus pares.

Estudos demonstraram que um clima escolar positivo pode ocasionar resultados positivos na aprendizagem e no desenvolvimento individual dos alunos, e um clima negativo pode obstruir a aprendizagem e o desenvolvimento ideal (Freiberg, 1998).

LaRusso e Selman (2011) sugerem que os alunos que frequentam escolas com um clima positivo revelam posturas conducentes à resolução de conflitos sem agressividade, e manifestam estar recetivos a participar em atividades de resolução de conflitos promovidas pela escola.

Assim, cabe à família demonstrar aos seus filhos as consequências negativas do emprego de táticas violentas, incentivando-os a analisar soluções alternativas a fim de gerirem os seus conflitos de forma construtiva (Ayas et al., 2010).

No que respeita às limitações deste trabalho, é de mencionar o uso de questionários de autorresposta para avaliar as variáveis em estudo, o que pode conduzir os participantes a responderem de acordo com o que consideram socialmente desejável. Outra limitação prende-se como o tamanho da amostra o que restringe a generalização dos resultados. Para se transpor esta limitação, e como pistas futuras, sugere-se utilizar amostras de tamanho superior, de ensino público e privado, em diferentes níveis de ensino.

Também em futuras investigações a efetuar no âmbito das táticas de gestão de conflitos e do clima de escola, consideramos necessário o desenvolvimento de estudos no sentido de observar a influência de outras variáveis de âmbito pessoal e motivacional com o objetivo de aumentar a variância explicada dos constructos em estudo. De igual modo, sugere-se que, em termos de opções metodológicas, pode ser pertinente analisar através de metodologia qualitativa algumas dimensões relativas a esta interligação entre clima de escola e táticas utilizadas pelos alunos, desig- 
nadamente aprofundar os significados que os comportamentos que os estudantes referem adotar têm na prática dessa gestão de conflitos.

A relevância do presente estudo passa por sugerir que o conflito interpessoal tem de ser entendido como algo a gerir de forma construtiva e proativa, dado que a sua ocorrência pode ser benéfica para o desenvolvimento pessoal dos alunos, e na construção de climas escolares positivos para a aprendizagem. De realçar que os resultados aqui encontrados indicam que o emprego de estratégias não violentas, alicerçadas na negociação tem um impacto positivo no clima de escola, e o emprego de estratégias de violência demostraram ter uma influência negativa no clima de escola.

Pretende-se, assim, que os resultados desta investigação possam contribuir para a formação de uma base de conhecimento que, apesar de limitada, permita o desenvolvimento de estratégias adequadas para gerir os conflitos entre alunos e a criação de ambientes escolares saudáveis, fomentando simultaneamente resultados positivos dos alunos.

Em suma, o contributo essencial da investigação será o de que importa implementar nas escolas programas orientados para o desenvolvimento de competências de relacionamento interpessoal, onde a colaboração e a negociação sejam entendidas como estratégias viáveis em situações de conflito. Trata-se de fomentar nas escolas a utilização de estratégias de gestão de conflito norteadas numa perspetiva de colaboração, em que todas as partes podem ser envolvidas como protagonistas na transformação da realidade, levando à criação de climas mais pacíficos e democráticos (Torrego, 2001).

\section{Referências}

Antunes, J. (2002). Motivação e atitudes dos jovens alunos face ao ambiente da aula e da escola. Tese de mestrado, Faculdade de Ciências, Universidade de Lisboa, Lisboa.

Ayas, T., Deniz, M., Kagan, M., \& Kenç, M. F. (2010). An investigation of conflict resolution strategies of adolescents. Procedia Social and Behavioral Sciences, 2(2), 3545-3551. http://www.sciencedirect.com/science/article/pii/S1877042810005896

Barros, N. (2010). Violência nas Escolas. Bullying. Lisboa: Bertrand Editora. http:// www.fnac.pt/Violencia-nas-Escolas-Bullying-Nazare-Barros/a312978

Blaya, C. (2008). Violência e Maus-Tratos em Meio Escolar. Lisboa: Horizontes Pedagógicos, Instituto Piaget. thttp://www.si.ips.pt/ese si/noticias geral.ver noticia?p $n r=8321$

Brunet, L. (1995). Clima de trabalho e eficácia de escola. In Nóvoa, A. (org.), As organizações escolares em análise. Lisboa: Publicações Dom Quixote.

Byrne, B. M. (2001). Structural Equation Modeling With AMOS - Basic Concepts, Applications, and Programming. New Jersey: Lawrence Erlbaum. Google books

Cascón, P. S. (2001). Educar en y para el conflicto. Cátedra UNESCO sobre Paz y Derechos UNESCO. Barcelona: Escola de Cultura de Pau.

Cornejo, R., \& Redondo, J. M. (2001). "El clima escolar percibido por los alumnos de enseñanza media". Revista Última Década, 15(9), 11-52. http://www.scielo.cl/ scielo.php?script=sci arttext\&pid=S0718-22362001000200002

Costa, M. E., \& Matos, P. M. (2006). Abordagem Sistémica do Conflito. Lisboa: Universidade Aberta. http://porftolio-ri-aice-jmonteiro.blogspot.com.co/2011/07/abordagem-sistemica-do-conflito.html 
Curran, P. J., West, S. G., \& Finch, J. F. (1997). The robustness of test statistics to nonnormality and specification error in confirmatory factor analysis. Psychological Methods, 1, 16-29. http://dx.doi.org/10.1037/1082-989X.1.1.16

Freiberg, H. J. (1998). Measuring school climate: Let me count the ways. Educational Leadership, 56(1), 22-26. http://www.ascd.org/publications/educational-leadership/sept98/ vol56/num01/Measuring-School-Climate@-Let-Me-Count-the-Ways.aspx

Hoy, W., \& Miskel, C. (2005). Education administration: Theroy, research, and practice (7 $7^{\mathrm{a}}$ ed.). New York: McGraw-Hill.

LaRusso, M., \& Selman, R. (2011). Early Adolescent Health Risk Behaviors, Conflict Resolution Strategies, and School Climate. Journal of Applied Developmental Psychology 32(6), 354-362. http://eric.ed.gov/?id=EJ947521

Lowe, B., Winzar, H., \& Ward, S. (2007). Essentials of SPSS for Windows versions 14 \& 15: a business approach. South Melbourne, Victória: Thomson Learning Australia. http://trove.nla.gov.au/work/32057658? selectedversion=NBD41556184

Martínez Zampa, D. (2005). Mediación educativa y resolución de conflictos: modelos de implementación. Buenos Aires: Ediciones Novedades Educativas. Google books

Martins, J. S. (2005). Violência e maus-tratos em contextos de socialização e delinquência juvenil. Tese de Doutoramento. Universidade de Santiago de Compostela, Faculdade de Psicologia, Espanha.

Paiva, M. O.A, \& Lourenço,A.A. (2010). Disrupção escolare rendimento académico: um estudo com modelos de equações estruturais. In Actas do VII Simpósio Nacional de Investigação em Psicologia. Braga: Universidade do Minho. http://www.academia.edu/17214919/ Disrup\%C3\%A7\%C3\%A3o Escolar e Rendimento Acad\%C3\%A9mico Um Estudo com Modelos de Equa\%C3\%A7\%C3\%B5es Estruturais

Paiva, M. O. A, \& Lourenço, A. A. (2011). Ambiente da sala de aula: um estudo de caso. Educação \& Filosofia, 25(49), 17 - 42. http://www.seer.ufu.br/index.php/EducacaoFilosofia/article/viewFile/13333/7679

Peterson, R. L., \& Skiba, R. J. (2001). Creating school climates that prevent violence. The Clearing House: A Journal of Educational Strategies, Issues and Ideas, 74(3), 155-63. http://www.tandfonline.com/doi/abs/10.1080/00098650109599183

Revez, M. (2004). Gestão das Organizações Escolares Liderança Escolar e Clima de Trabalho. Um estudo Caso. Chamusca: Edições Cosmos.

Steffgen, G., Recchia, S., \& Viechtbauer; W. (2013). The link between school climate and violence in school: A meta-analytic review. Aggression and Violent Behavior, 18(2), 300-309.

Straus, M. A. (1979). Measuring intrafamily conflict and violence: The Conflict Tactics (CT) Scales. Journal of Marriage and Family, 41(1), 75-86. https://www.jstor.org/ stable/351733?seq=1\#page scan tab contents

Straus, M. A., Hamby, S. L., Finkelhor, D., Moore, D. W., Runyan, D. (1998). Identification of child maltreatment with the parent-child conflict tactic \& scales: Development and psychometric data for a national sample of American parents. Child Abuse and Neglect, 22(4), 249-270. http://www.ncbi.nlm.nih.gov/pubmed/9589178

Torrego, J. C. (2001). Modelos de regulación de la convivencia. Cuadernos de Pedagogía, 304, 20-28. https://dialnet.unirioja.es/ejemplar/4072

Torrego, J. C. (2007). Convivencia, Conflicto y Escuela. In J. M. Moreno Olmedilla \& F. Luengo Orcajo. Construir ciudadanía e prevenir conflictos (pp. 49-59). Madrid: Wolters Kluwer. http://www.scielo.org.mx/pdf/polcul/n32/n32a10.pdf

Ullman, J. B., \& Bentler, P. M. (2004). Structural Equation Modeling. In M. Hardy \& A. Bryman (Eds), Handbook of data analysis (pp. 431-458). London: Sage.

Zullig, K. J., Huebner, E. S., \& Patton, J. M. (2011). Relationships among school climate domains and school satisfaction. Psychology in the Schools, 48(2), 133-145. http://onlinelibrary.wiley.com/doi/10.1002/pits.20532/abstract 